\title{
Staphylococcus haemolyticus strains target mitochondria and induce caspase-dependent apoptosis of macrophages
}

\author{
Sylwia Krzymińska $\cdot$ Ewa Szczuka • \\ Adam Kaznowski
}

Received: 2 April 2012/Accepted: 22 May 2012/Published online: 2 June 2012

(C) The Author(s) 2012. This article is published with open access at Springerlink.com

\begin{abstract}
The aim of this study was to investigate the interaction of Staphylococcus haemolyticus strains with a macrophage cell line. Infection with the strains resulted in macrophage injury. All strains exhibited cytotoxic effects towards $\mathrm{J} 774$ cells. Moreover, the bacteria triggered apoptosis of the cells. The lowest apoptotic index did not exceed $21 \%$, whereas the highest reached $70 \%$ at $24 \mathrm{~h}$ and $85 \%$ at $48 \mathrm{~h}$ after infection. Incubation with the bacteria caused loss of mitochondrial membrane potential $(\Delta \Psi \mathrm{m})$ in macrophages. The pro-apoptotic activity of the strains was blocked by a pan-caspase inhibitor z-VAD-fmk, indicating the involvement of caspases in the bacteriamediated cell death. We observed that the induction of macrophage apoptosis could constitute an important mechanism of pathogenesis by which $S$. haemolyticus strains evade host immune defences and cause disease.
\end{abstract}

Keywords Staphylococcus haemolyticus · Genetic diversity $\cdot$ Cytotoxicity $\cdot$ Apoptosis

\section{Introduction}

Among the coagulase-negative staphylococci (CoNS), Staphylococcus haemolyticus strains are the second

S. Krzymińska $(\bowtie) \cdot$ E. Szczuka · A. Kaznowski Department of Microbiology, Faculty of Biology, A. Mickiewicz University, ul. Umultowska 89, 61-614 Poznań, Poland e-mail: sylkrzym@amu.edu.pl most commonly isolated bacteria that play important roles in hospital-acquired opportunistic infections. Infection with these bacteria may play a significant role in patients with underlying disease, such as those with prosthetic devices, surgical patients, individuals undergoing dialysis, or patients with diabetes. CoNS cause septicemia, endocarditis, otitis, urinary tract illnesses and peritonitis (Falcone et al. 2007; Falcone et al. 2004; Ertem et al. 2010). Previous studies have documented outbreaks or persistence of S. haemolyticus strains that affected patients in intensive care units (Klingenberg et al. 2007; Mazzariol et al. 2012). An association between liver abscess and colonic cancer and infection with $S$. haemolyticus strains has been noted (Gamberini et al. 2006).

The mechanisms of $S$. haemolyticus pathogenesis are still poorly understood. The genomes of $S$. haemolyticus clinical isolates contain genes encoding putative virulence factors, which include hemolysins, adhesins, exonucleases and proteases (Takueschi et al. 2005). The pathogenesis may be also related to the production of an extracellular polysaccharide slime that permits the bacteria to adhere to polystyrene surfaces and to colonize catheters and prosthetic heart valves (Spare et al. 2003). However, there is still a lack of knowledge regarding the contribution of these factors to the pathogenicity of S. haemolyticus.

Cell-mediated killing represents the major defense mechanism against host nonspecific immunity (Sansonetti and Di Santo 2007). Macrophages contribute to the primary line of innate defence against bacterial 
pathogens by providing their removal and destruction at the level of the epithelial barrier. Therefore, many bacterial pathogens have developed specific strategies to subvert the effective antimicrobial immune response of the cells in order to avoid the innate immune defence of the host. The ability of bacterial pathogens to promote apoptosis of immune cells may be important for bacterial survival and escape from the host immune defence and is implicated in the mechanism of pathogenesis (Sansonetti and Di Santo 2007; Böhme and Rudel 2009). Cells undergoing apoptosis show a characteristic sequence of morphological and biochemical features including membrane blebbing, cellular shrinkage and condensation of chromatin and degradation of DNA by cleavage to internucleosomalsized fragments.

In this study, we analyzed interactions of S. haemolyticus strains with macrophages to understand better the pathogenic mechanisms of the bacteria. Moreover, we determined the clonal structure of the strains to detect whether one predominant clone is responsible for infections of many patients or genetically unrelated strains caused diseases.

\section{Materials and methods}

Bacterial strains

Thirty S. haemolyticus strains were used in the study. All isolates were identified to the species level by using biochemical tests of the API Staph identification system (bioMérieux). The strains were isolated from: blood, urine, a postoperative wound and skin (Table 1). The isolates were maintained at $-75{ }^{\circ} \mathrm{C}$ in tryptic soy broth (TSB, Difco) containing $50 \%$ (vol/vol) glycerol. Escherichia coli K-12 C600 strain was used as the negative control.

\section{Clonal analysis by REP-PCR typing}

Bacterial DNA was isolated with genomic DNA Plus kit (A\&A Biotechnology, Poland). The REP-PCR method uses primers complementary to repetitive extragenic palindromic (REP) elements of bacterial genomic DNA (Versalovic et al. 1991). The amplicons were electrophoresed in $1.5 \%$ agarose gels. The DNA in gels was stained with ethidium bromide, visualized on a UV light transilluminator and documented with
Table 1 Staphylococcus haemolyticus strains used in the study

\begin{tabular}{ll}
\hline $\begin{array}{l}\text { Source of origin } \\
\text { (number of strains) }\end{array}$ & Isolates number \\
\hline Blood (15) & $\begin{array}{c}\text { MPU Sh1, 6, 7, 11, 13, 16, 17, 19, 20, } \\
22,23,24,25,26,30\end{array}$ \\
Wound (4) & MPU Sh4, 9, 15, 28 \\
Secretion (4) & MPU Sh2, 8, 18, 29 \\
Medical devices (3) & MPU Sh10, 12, 21 \\
Urine (2) & MPU Sh3, 5 \\
Skin (2) & MPU Sh14, 27 \\
\hline
\end{tabular}

the V.99 Bio-Print system (Vilber Lourmat, Torcy, France). Computer analysis was carried out by using GelCompar II (version 3.5; Applied Maths, Belgium) software. The similarity between fingerprints was calculated with the Dice coefficient. Cluster analysis was performed by using the unweighted pair-group method with average linkages (UPGMA).

Macrophage cell line

The murine macrophage cell line $\mathbf{J} 774$ was maintained in growth medium (GM), containing RPMI 1640 supplemented with $10 \%$ heat-inactivated fetal calf serum, gentamicin $(5 \mu \mathrm{g} / \mathrm{ml})$ and $2 \mathrm{mM}$ L-glutamine. Cells were seeded in $100 \mu \mathrm{l}$ of suspension $\left(1 \times 10^{4}\right.$ cells per well) and incubated at $37^{\circ} \mathrm{C}$ in the atmosphere of $5 \% \mathrm{CO}_{2}$ (Krzymińska et al. 2009).

Cytotoxic activity

The bacteria were grown in TSB on a rotary shaker $(150 \mathrm{rpm})$ at $37^{\circ} \mathrm{C}$ for $24 \mathrm{~h}$ and centrifuged at $2,000 \times g$ for $20 \mathrm{~min}$. The supernatants were sterilized through $0.22 \mu \mathrm{m}$-pore size membrane filters MillexGV (Millipore). Monolayers of J774 cells were incubated with $100 \mu \mathrm{l}$ of bacterial culture filtrate for $24 \mathrm{~h}$. Some wells were incubated with GM and E. coli $\mathrm{K}-12 \mathrm{C} 600$ as negative controls. Cytotoxicity was determined quantitatively based on MTT [3-(4,5dimethylthiazol-2-yl)-2,5 diphenyltetrazolium bromide] (Sigma) uptake and reduction in tetrazoliumbased colorimetric assay as described previously (Krzymińska et al. 2009).

Additionally, the number of viable cells was assessed by trypan blue exclusion. The suspension of trypsynized cells was stained with $0.1 \%$ trypan blue 
(Sigma) for $3 \mathrm{~min}$ at room temperature and counted in a hemocytometer. The cells that excluded the stain were considered as viable, whereas those stained blue were considered dead.

\section{Cell-contact and extracellular hemolytic activity}

To obtain a quantitative measure of hemolytic activity, bacterial cell suspension and extracellular supernatants were utilized. The cells from tryptic soy agar (TSA, Difco) were washed in PBS and diluted to optical density at $600 \mathrm{~nm}\left(\mathrm{OD}_{600}\right)=0.3$ (Krut et al. 2003). Fresh group 0 human blood was obtained from volunteer donors at a Blood Center. The plasma was discarded following centrifugation $(250 \times g$ for $10 \mathrm{~min}$ ) and erythrocytes were washed three times with sterile PBS. An equal volume of $1 \%$ ( $\mathrm{vol} / \mathrm{vol})$ erythrocyte solution was mixed with bacterial culture supernatant or suspension containing $1 \times 10^{7}$ bacterial cells. After 1 -h incubation at $37{ }^{\circ} \mathrm{C}$, the mixture was centrifuged $(250 \times g$ for $10 \mathrm{~min})$ and further incubated for $3 \mathrm{~h}$. The absorbance of supernatants was measured at $540 \mathrm{~nm}$. Control tubes for spontaneous hemolysis contained $1 \%$ erythrocyte solution and distilled water. The results were expressed as the percentage of total $(100 \%)$ hemolysis (Shimuta et al. 2009).

\section{Infection conditions}

J774 cells $\left(1 \times 10^{4}\right.$ cells per well $)$ were infected with S. haemolyticus cell suspension diluted in GM to a concentration of $1 \times 10^{7} / \mathrm{ml}$. The viability of the bacteria was determined by plating dilutions on TSB agar and counting $\mathrm{CFU} / \mathrm{ml}$. Infection was performed at MOI (number of cells: bacteria ratio) of 1:100 for $90 \mathrm{~min}$ at $37{ }^{\circ} \mathrm{C}$ (Krut et al. 2003). Next, the monolayer was washed with PBS (Phosphate-buffered saline, Biomed) and incubated with GM containing $100 \mu \mathrm{g} / \mathrm{ml}$ gentamicin for $2 \mathrm{~h}$ at $37^{\circ} \mathrm{C}$. After washing three-times with PBS, the cells were incubated in the medium without gentamicin (Alexander et al. 2003).

Determination of the percentage of apoptotic cells by fluorescence microscopy

The monolayer after infection was double stained with a solution containing $100 \mu \mathrm{g} / \mathrm{ml}$ of acridine orange (AO) and ethidium bromide (EB) for $2 \mathrm{~min}$ and visualized by Zeiss confocal laser-scanning microscopy. The characteristics of the cells were recorded according to the colour and structure of the chromatin and cells assigned to three different groups: viable, apoptotic and necrotic cells (Krzymińska et al. 2011). We determined apoptotic (AI) and necrotic indexes (NI) as the percentage of apoptotic and necrotic cells, respectively.

To determine the involvement of caspases in S. haemolyticus-induced apoptosis, J774 cells were incubated with a broad-spectrum caspase inhibitor Z-Val-Ala-Asp( $O$-methyl)-fluoromethylketone (z-VADfmk, R\&D Systems) for $3 \mathrm{~h}$ prior to the infection and continued for $48 \mathrm{~h}$ after the infection. After 24 and $48 \mathrm{~h}$ the infected cells were examined by acridine orange and ethidium bromide staining.

\section{Assessment of DNA fragmentation}

Degradation of nuclear DNA by cleavage to internucleosomal-sized fragments can be used as a biochemical marker of apoptosis. DNA was isolated from the infected and control cells 24 and 48 h after gentamicin treatment and fragmentation was assessed according to the method described previously (Krzymińska et al. 2011).

Determination of mitochondrial transmembrane potential

Mitochondrial transmembrane potential $(\Delta \psi)$ was analysed using the $\Delta \psi$-sensitive dye tetramethylrhodamine ethyl ester (TMRE, Sigma) as described previously (Krzyminska et al. 2011). In brief, infected cells were trypsinized and stained with $10 \mathrm{nM}$ TMRE for $2 \mathrm{~min}$ at room temperature. After washing with PBS, the cells were imaged with an Axiovert $200 \mathrm{M}$ (Zeiss) laser scanning confocal microscope at exitation $\lambda 568 \mathrm{~nm}$ and emission $\lambda>590 \mathrm{~nm}$ by using a long-pass emission filter (Krzymińska et al. 2011).

\section{Statistical analysis}

The values of the percentage cytotoxicity, viability, AI, NI and $\Delta \psi$ were determined in triplicate wells, and the data represent the means \pm standard deviations (SD) from at least two separate experiments. A statistical analysis of significance was done by using a one-way analysis of variance (ANOVA) followed by 
Tukey's HSD post hoc test for group comparison. The linear regression analysis was used to examine pairwise correlation between the Apoptotic Index, cytotoxicity and $\Delta \Psi_{\mathrm{m}}$, thus the Pearson correlation coefficient was determined. $P$ values of $<0.05$ were considered statistically significant.

\section{Results}

Clonal analysis

A dendrogram based on the REP-PCR analysis of DNA from the $S$. haemolyticus strains studied is presented in Fig. 1. We found various REP-PCR banding patterns from 7 to 15 bands (perpendicular lines). Only two clusters contained genetically closely related strains. The highest degree of similarity $(S=92 \%)$ was obtained for two strains of $S$. haemolyticus isolated from the blood of two patients. Hospitalization of these patients took place at different times but at the same hospital ward. The second cluster

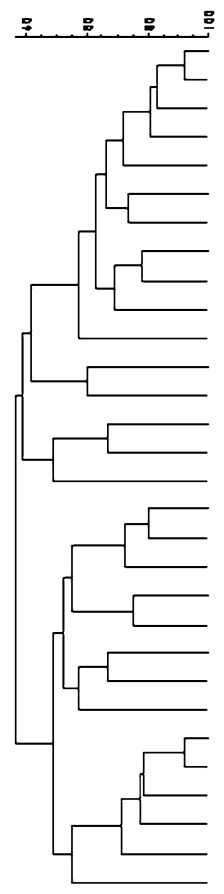

| | || | || || || | || ||| || ||| | ||| || || |||

|| ||| | |||

|| || | || | |||

|| ||| ||

| | || || |||

| || || || ||

|| |||||||||| $\mid$

| ||||||| ||| |

|II||l| |||

|| ||| |

|| |||||||||| |

| II I| || |

| || | || || ||

|| | | | | | ||||||

| || | || || ||

| | | || | || || | | |

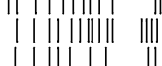

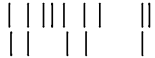

II III II

|| $|\|| \mid$

|| ||| || || ||

|| | | | || || | | |

|| | || || || ||

|1 $111 \mid 11$

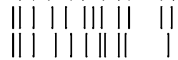

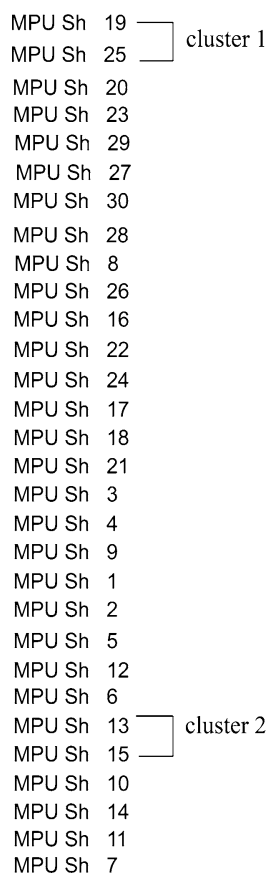

Fig. 1 Dendrogram generated from REP-PCR fingerprint patterns of Staphylococus haemolyticus strains by the unweighted pair-group method (UPGMA) with arithmetic means. The Dice band-based similarity coefficient was calculated with band position tolerance of $1 \%$. The scale bar represents similarity
( $S=91 \%)$ was composed by two strains isolated from bedsore and blood. These strains were isolated from two patients treated in different hospital wards. The remaining strains showed distinct REP-PCR fingerprint patterns and were considered genetically unrelated. The fact that only two clusters were identified along with 26 unique genotypes indicates a large genetic diversity among $S$. haemolyticus isolates obtained from patients treated in a single hospital.

\section{Cytotoxic activity of $S$. haemolyticus strains}

The capacity of cell-free supernatants to impair J774 cell viability was determined at $24 \mathrm{~h}$. The culture medium and the non-pathogenic E. coli $\mathrm{K}-12 \mathrm{C} 600 \mathrm{did}$ not exhibit cytotoxic effects on $\mathbf{J} 774$ cells (Fig. 2a). All strains of $S$. haemolyticus exhibited cytotoxic effects which were evident by detachment of the cells from the surface of the wells (Fig. 2b). Three strains $(10 \%)$ showed the low cytotoxic activity (Table 2). By contrast, high activity was observed in culture supernatants of $7(23 \%)$ isolates originating from blood, wounds and respiratory secretions.

The trypan blue exclusion assay revealed that the percentage of infected cells that remained viablee at $24 \mathrm{~h}$ ranged between $41 \pm 2.1$ and $87 \pm 4.7 \%$. The viability decreased to values between $25 \pm 3.7$ and $65 \pm 2.8 \%$ at $48 \mathrm{~h}$. The control J774 cells incubated with growth medium alone had viability of $94 \pm 1.2$ and $91 \pm 1.8 \%$ at 24 and $48 \mathrm{~h}$, respectively.

Hemolytic activity

The results showed that $S$. haemolyticus strains produced extracellular toxins which were able to lyse human erythrocytes (Table 2). The hemolytic activity ranged between 2.6 and $97.1 \%$. High activity was observed for one $(3 \%)$ strain. Low activity was demonstrated by 17 $(57 \%)$ strains. We observed a low percentage of cellcontact hemolysis, which was in the range from 1.7 to $7.2 \%$. The non-pathogenic E. coli strain K-12 C600 did not demonstrate hemolytic activity.

Assessment of apoptosis and necrosis of infected J774 cells

Morphological evidence of apoptosis and necrosis of S. haemolyticus-infected cells was observed after AO and EB staining followed by confocal microscope 

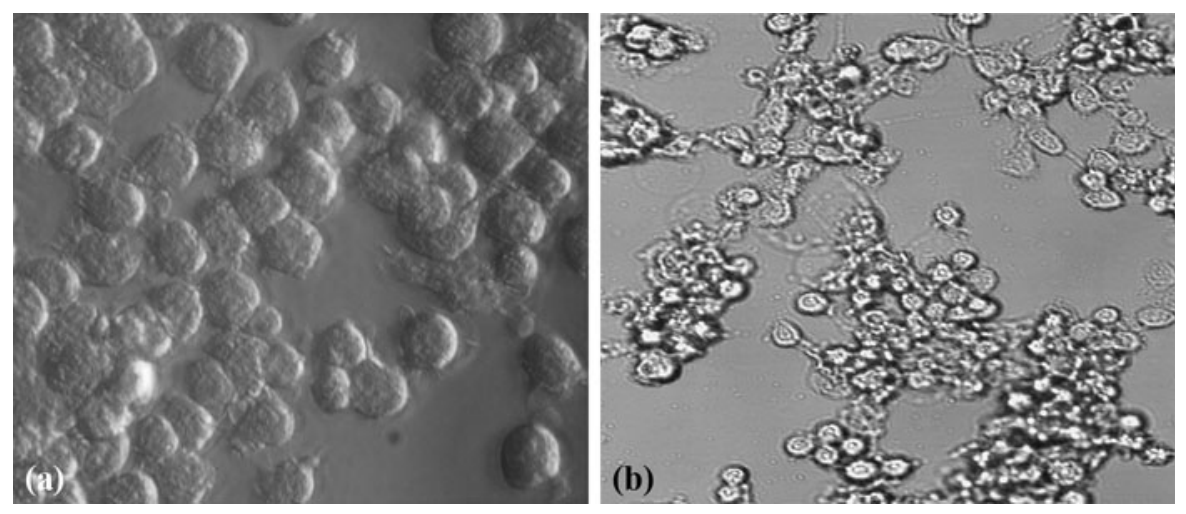

Fig. 2 Cytotoxic effect of S. haemolyticus strains to J774 cells. The monolayer was incubated with culture medium (a), S. haemolyticus MPU Sh7 strain (b) and observed using an inverted microscope

analysis. Double staining revealed loss of cell membrane integrity and allowed discrimination between viable, apoptotic and necrotic cells. AO stains live cells and renders the nuclei of live cells green (Fig. 3a). EB is taken up by the cells only when cytoplasmic membrane integrity is lost, staining the nuclei of apoptotic cells red (Fig. 3b) with apoptotic bodies (Fig. 3c). The apoptotic indexes (AI) varied among the strains (Table 2). The highest AI, ranging from $41.2 \pm 3.4$ to $49.7 \pm 4.1 \%$ at $24 \mathrm{~h}$ after infection, was observed in phagocytes incubated with 10 (33\%) strains. In contrast, the lowest AI, between $15.6 \pm 1.8$ and $21.2 \pm 2.1 \%$, was caused $9(30 \%)$ strains. The percentage of apoptotic cells increased at $48 \mathrm{~h}$ after the infection. The highest AI, ranging from $77.9 \pm 4.1$ to $84.6 \pm 3.2 \%$, was observed in macrophages infected with $13(43 \%)$ strains whereas the lowest AI, ranging from $37.2 \pm 2.7$ to $48.8 \pm 1.3 \%$, was revealed by $\mathrm{J} 774$ cells incubated with $5(17 \%)$ strains. The AI were reduced in the presence of the pan-caspase inhibitor to the range between 6.4 and $9.1 \%$ at $24 \mathrm{~h}$, and 11.7 and $15.3 \%$ at $48 \mathrm{~h}$, suggesting that apoptosis depends on caspase activation.

Twenty-two (73\%) and 24 (80\%) S. haemolyticus strains caused necrosis, respectively at 24 and $48 \mathrm{~h}$. The highest NI, ranging from $9.1 \pm 1.3 \%$ to $17.6 \pm 2.1 \%$ at $24 \mathrm{~h}$, was detected for $5(17 \%)$ strains. At $48 \mathrm{~h}$ the NI decreased for $9(30 \%)$ strains, and was between $11.7 \pm 1.8$ and $24.4 \pm 3.1 \%$. These strains were isolated from urine (MPU Sh3, 5), blood (MPU Sh19, 20), drain (MPU Sh12) and skin (MPU Sh14, 27), a catheter (MPU Sh21) and respiratory secretion (MPU Sh18).
DNA fragmentation is a key feature of apoptosis. We observed fragmentation of nuclear DNA in $\mathbf{J 7 7 4}$ cells infected with $13(43 \%)$ strains at $24 \mathrm{~h}$ after infection (not shown). At $48 \mathrm{~h}$, fragmentation was observed to be caused by $22(73 \%)$ strains.

Mitochondrial transmembrane potential $\left(\Delta \Psi_{\mathrm{m}}\right)$

To gain insights into the pathway involved in $S$. haemolyticus-induced apoptosis of macrophages, we determined whether the process involved mitochondrial damage by the collapse of transmembrane potential. We therefore used a mitochondrion-selective fluorescent dye, whose uptake depends on an intact membrane. The dye exhibits changing colour intensity depending on $\Delta \psi$. An analysis at the single cell level revealed a large difference of TMREfluorescence intensity between live and infected apoptotic J774 cells (Fig. 4a, b). The highest fluorescence intensity, ranging from $197 \pm 15.7$ to $210 \pm 21.3$ F.U, was observed in live cells. The intensity decreased to the range between $31.4 \pm 11.3$ and $36.1 \pm 13.7$ F.U in apoptotic and necrotic cells. The cationic dye accumulates in the mitochondria in proportion to $\Delta \psi$ and therefore the decrease in fluorescence intensity indicates depolarization of the mitochondrial membrane. We examined TMRE fluorescence in 25 cells in order to assess average $\Delta \Psi_{\mathrm{m}}$ in $S$. haemolyticus-infected cells (Table 2). High dissipation of fluorescence intensity was observed in cells infected with 7 (23\%) and 12 (40\%) strains at 24 and $48 \mathrm{~h}$, respectively. The highest reduction of $\Delta \Psi_{\mathrm{m}}$ was visible as a lowering of 
Table 2 The comparison of apoptotic index of J774 cells infected with S. haemolyticus strains at 24 and $48 \mathrm{~h}$ without and with the pan-caspase inhibitor, extracellular cytotoxic and hemolytic activity, and transmembrane mitochondrial potential $\left(\Delta \Psi_{\mathrm{m}}\right)$

\begin{tabular}{|c|c|c|c|c|c|}
\hline \multirow[t]{2}{*}{ Strain number } & \multicolumn{2}{|c|}{ Apoptotic index ${ }^{a}(\%)$} & \multirow{2}{*}{$\begin{array}{l}\text { Cytotoxic } \\
\text { activity }^{\mathrm{b}}(\%)\end{array}$} & \multirow{2}{*}{$\begin{array}{l}\text { Hemolytic } \\
\text { activity }^{\mathrm{c}}(\%)\end{array}$} & \multirow[t]{2}{*}{$\Delta \Psi_{\mathrm{m}}^{\mathrm{d}} \times 10^{2}(\mathrm{~F} . \mathrm{U})$} \\
\hline & $24(\mathrm{~h})$ & 48 (h) & & & \\
\hline MPU Sh4 & $49.7 / 6.8$ & $83.1 / 15.3$ & 61.7 & 26.9 & $25.8 / 15.4$ \\
\hline MPU Sh9 & $48.4 / 7.1$ & $81.3 / 14.8$ & 61.2 & 15.3 & $29.6 / 7.9$ \\
\hline MPU Sh16 & $47.2 / 6.3$ & $81.6 / 15.1$ & 49.1 & 5.7 & $22.8 / 14.1$ \\
\hline MPU Sh7 & $47.1 / 9.1$ & $84.6 / 14.9$ & 59.4 & 23.4 & $35.9 / 7.1$ \\
\hline MPU Sh14 & $46.8 / 7.2$ & $80.7 / 11.7$ & 58.1 & 98.0 & $27.3 / 12.7$ \\
\hline MPU Sh3 & $45.1 / 8.7$ & $78.1 / 15.1$ & 36.2 & 18.8 & $32.7 / 10.9$ \\
\hline MPU Sh13 & $43.7 / 6.1$ & $81.2 / 14.6$ & 52.7 & 6.8 & $24.9 / 8.9$ \\
\hline MPU Sh24 & $42.8 / 7.5$ & $79.6 / 11.8$ & 46.5 & 5.4 & 21.9/9.1 \\
\hline MPU Sh29 & $42.1 / 6.4$ & $78.3 / 15.2$ & 51.3 & 41.3 & $26.1 / 13.2$ \\
\hline MPU Sh23 & $49.2 / 8.9$ & $83.7 / 14.2$ & 63.1 & 11.9 & $33.1 / 9.2$ \\
\hline MPU Sh28 & $39.3 / 6.8$ & $81.6 / 11.8$ & 48.6 & 39.3 & $34.1 / 9.8$ \\
\hline MPU Sh30 & $38.1 / 6.1$ & $81.1 / 12.6$ & 41.2 & 37.3 & $30.9 / 9.7$ \\
\hline MPU Sh10 & $37.8 / 7.1$ & $69.2 / 14.9$ & 38.9 & 29.5 & $39.7 / 11.2$ \\
\hline MPU Sh8 & $33.7 / 6.2$ & $78.1 / 13.7$ & 36.1 & 2.5 & $26.9 / 9.0$ \\
\hline MPU Sh15 & $32.6 / 6.7$ & $77.9 / 15.3$ & 25.7 & 4.0 & $31.6 / 11.1$ \\
\hline MPU Sh22 & $31.7 / 7.1$ & $75.1 / 11.9$ & 35.6 & 11.8 & $30.1 / 22.6$ \\
\hline MPU Sh2 & 28.6/9.1 & $74.9 / 12.8$ & 30.1 & 4.8 & $56.5 / 17.3$ \\
\hline MPU Sh27 & $27.1 / 8.9$ & $71.4 / 14.6$ & 16.9 & 7.6 & $39.1 / 29.1$ \\
\hline MPU Sh21 & $25.7 / 7.6$ & $63.4 / 11.7$ & 13.6 & 31.4 & $56.5 / 18.7$ \\
\hline MPU Sh11 & $25.1 / 6.7$ & $56.3 / 11.9$ & 12.7 & 5.7 & $53.2 / 37.6$ \\
\hline MPU Sh18 & $24.4 / 6.1$ & $52.8 / 12.4$ & 31.7 & 13.9 & $40.8 / 31.3$ \\
\hline MPU Sh19 & 21.2/8.9. & $63.9 / 15.2$ & 21.7 & 11.2 & $38.9 / 21.6$ \\
\hline MPU Sh20 & $20.8 / 6.4$ & $48.8 / 11.8$ & 19.5 & 6.8 & $41.7 / 26.4$ \\
\hline MPU Sh1 & $19.5 / 6.7$ & $65.4 / 15.1$ & 10.3 & 45.5 & $41.8 / 10.2$ \\
\hline MPU Sh26 & $18.9 / 8.4$ & $66.8 / 14.9$ & 18.4 & 4.9 & $53.1 / 19.1$ \\
\hline MPU Sh12 & $18.1 / 6.2$ & $41.7 / 11.8$ & 17.1 & 6.1 & $44.6 / 29.8$ \\
\hline MPU Sh17 & $17.8 / 6.3$ & $37.2 / 12.3$ & 8.7 & 3.5 & $55.8 / 28.6$ \\
\hline MPU Sh25 & $16.4 / 6.5$ & $62.1 / 15.1$ & 27.1 & 8.4 & $43.7 / 16.1$ \\
\hline MPU Sh5 & $16.1 / 6.1$ & $43.2 / 11.9$ & 11.4 & 3.6 & $52.7 / 32.6$ \\
\hline MPU Sh6 & $15.6 / 7.3$ & $39.1 / 11.7$ & 15.3 & 27.5 & $54.1 / 25.7$ \\
\hline E. coli $\mathrm{K}-12 \mathrm{C} 600$ & $5.7 / \mathrm{ND}$ & 11.9/ND & 0 & 0 & $52.7 / 41.3$ \\
\hline
\end{tabular}

\section{ND not determined}

${ }^{a}$ The percentage of apoptotic cells after AO and EB staining at 24 and $48 \mathrm{~h}$ after infection without pan-caspase inhibitor/with the inhibitor

b The percentage of extracellular cytotoxicity measured by MTT assay

c The percentage of total extracellular hemolysis, compared to $100 \%$ lysis in distilled water was performed at $4 \mathrm{~h}$ after infection by using a suspension of $1 \%$ human erythrocytes

d TMRE fluorescence intensity per 25 cells at $24 / 48 \mathrm{~h}$

fluorescence intensity to $890 \pm 23.6$ F.U on 25 cells. J774 cells incubated with $E$. coli $\mathrm{K}-12 \mathrm{C} 600$, as a negative control, revealed $5.2 \pm 0.7 \times 10^{3}$ and $4.1 \pm 0.3 \times 10^{3}$ F.U, respectively at 24 and $48 \mathrm{~h}$.
The Pearson linear correlation test revealed positive correlations between AI of infected J774 cells and cytotoxic activity $(r=0.64, p<0.01)$, and between $\mathrm{AI}$ and loss of $\Delta \Psi_{\mathrm{m}}(r=-0.57, p<0.01)$ at $24 \mathrm{~h}$. 

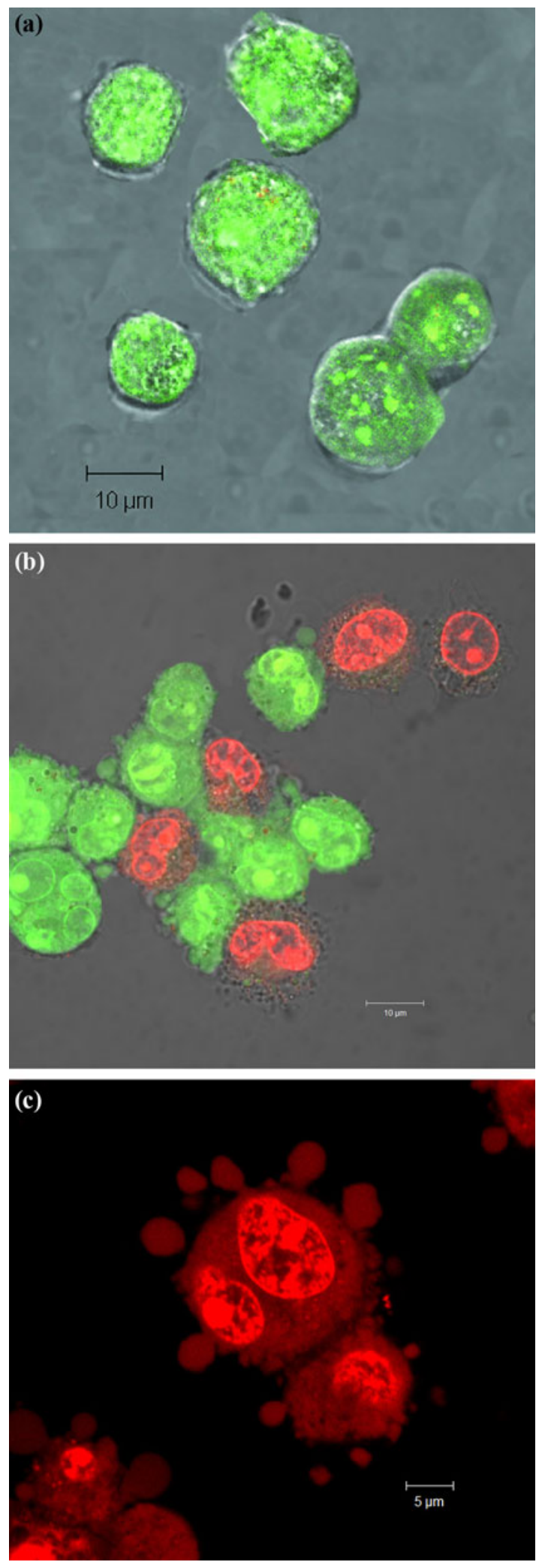

4 Fig. 3 Apoptosis of J774 cells during S. haemolyticus infection. The macrophages were incubated with: culture medium (a), S. haemolyticus MPU Sh7 (b, c), cells with apoptotic bodies (c). The cells were observed using a laser scanning confocal microscope after AO and EB staining (green cells-live, redapoptotic). (Color figure online)

\section{Discussion}

The present study provides evidence that infection with $S$. haemolyticus strains caused alterations of macrophages and induced apoptosis of the cells. While S. haemolyticus is often considered to be of low virulence, there are also reports for its association with increased mortality (Worth and Slavin 2009). Phagocytes, such as macrophages, are essential effectors of the immune response against pathogenic bacteria. Therefore, the ability of pathogenic strains to circumvent the effector functions of the cells could be an important mechanism for the successful establishment of infection (Rudel et al. 2010). The results presented in the present study provide evidence that all S. haemolyticus strains were cytotoxic to macrophages. We observed that $23 \%$ of them had cytotoxic activity which caused destruction above $50 \%$ of macrophages. Previously, Zell et al. (2008) have analyzed the cytotoxic activity of CoNS isolated from food, other than S. haemolyticus. They reported that 18 of 35 strains were toxin positive and some of them produced more than one toxin. The most prevalent staphylococcal enterotoxins (SE) were SED and SEH, whilst two strains produced exfoliative toxin A. Vasconcelos et al. (2011) observed that $40 \%$ of $S$. haemolyticus strains that originated from newborns hospitalized at a neonatal unit contained staphylococcal enterotoxins G (SEG) genes. High cytotoxic activity (more than $50 \%$ ) to keratinocytes has also been observed for 7 of 35 of Staphylococcus aureus clinical isolates (Krut et al. 2003). In the present study, we noticed positive correlations between cytotoxic and hemolytic activities for $9(30 \%)$ strains which suggests that cytotoxicity was evoked by hemolysins or pore-forming toxins. Previously, Butt et al. (1998) have reported that $S$. haemolyticus isolates from patients with chronic orofacial muscle pain produce $\delta$ hemolysins.

In the present study we observed in the trypan blue exclusion assay that infection with $S$. haemolyticus strains induced the cell death in macrophages in the range approximately from 13 to 59 and 35 to $75 \%$ at 


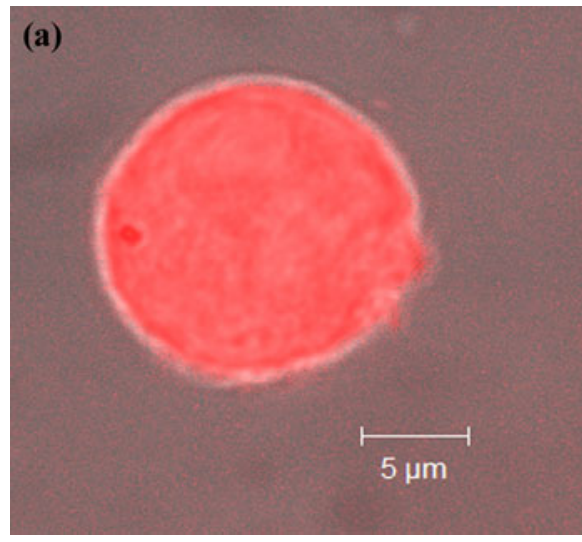

Fig. 4 Mitochondrial membrane potential of J774 cells at the single cell level after 24 h-incubation with: culture medium (a), S. haemolyticus MPU Sh 7 (b). The infected cells were

24 and $48 \mathrm{~h}$, respectively. Fluorescent microscope observations after $\mathrm{AO} / \mathrm{EB}$ staining revealed that the strains caused cell death by apoptosis. The apoptotic activity of $S$. haemolyticus strains varied among different isolates. High apoptotic activity, above $60 \%$, was observed for $10(33 \%)$ strains at $24 \mathrm{~h}$ and this increased to a range from 78 to $85 \%$ for 13 (43\%) strains at $48 \mathrm{~h}$. These strains originated from blood (6), wounds (4), secretions (2), skin and urine. This suggests this is a mechanism to subvert the functions of macrophages. The induction of cell death may suppress the effective antimicrobial immune responses of macrophages to avoid the innate immune defence of the host. The formation of apoptotic cells was prevented by preincubation with a pan-caspase inhibitor, indicating that caspases are involved with $S$. haemolyticus-induced cell death. Previously, Haslinger-Löffler et al. (2005) have observed a similar apoptotic activity to endothelial cells induced by clinical S. aureus isolates. The production of virulence factors by $S$. haemolyticus strains has not been clearly defined yet. The whole genome sequencing and comparative genomics of Staphylococcus spp. have identified genes of $S$. haemolyticus strains coding for some putative factors (Takueschi et al. 2005). However, there is still a lack of knowledge regarding the contribution of these factors to the pathogenesis of the bacteria (Otto 2004). In the present study, the Pearson linear correlation test revealed positive correlations between AI of infected $\mathrm{J} 774$ cells and cytotoxic activity, which suggested that apoptosis of the cells was associated with the cytotoxic activity of $S$.

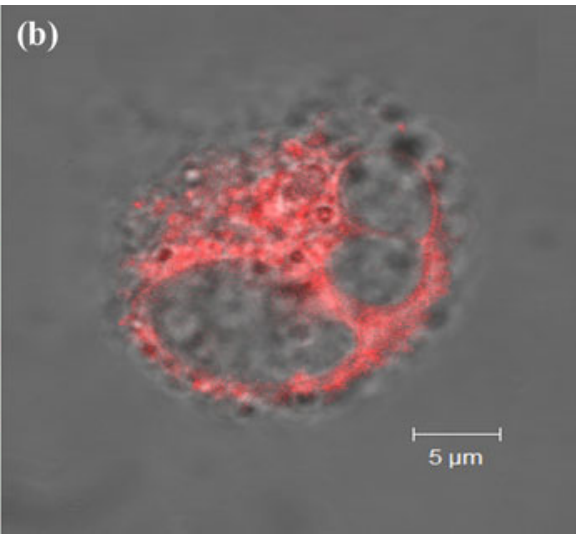

trypsinized and stained with $10 \mathrm{nM}$ TMRE. The fluorescence was visualized by laser confocal microscopy

haemolyticus strains. Production by CoNS of extracellular $\delta$-toxins and proteases such as metalloproteases and serine proteases which could exert cytotoxic activity has been previously observed (Harris and Richards 2006). In addition, strains of $S$. haemolyticus carry genes encoding capsular polysaccharide (CP). The $S$. haemolyticus $\mathrm{CP}$ has antiphagocytic properties and capsulated strains are resistant to opsonophagocytic killing by human neutrophils (Flauhaut et al. 2008).

There is increasing evidence that apoptosis can be triggered by a wide range of bacterial pathogens which have evolved different survival strategies, leading to the development of infection symptoms but there is little data concerning Staphylococcus spp. strains. Essmann et al. (2003) have reported that $\alpha$-toxin, the major hemolysin of $S$. aureus, induces pore-forming cytotoxicity, which evokes apoptosis of breast carcinoma cells. These strains also secrete Panton-Valentine leukocidin (PVL), a pore-forming toxin which induces neutrophil cell death by apoptosis or necrosis, depending on PVL concentration (Genestier et al. 2005). Haslinger-Löffler et al. (2005) have suggested that $S$. aureus strains with cytotoxic and invasive activity induce caspase-dependent apoptosis of endothelial cells. This would explain the ability of the bacteria to invade the circulation from localized sites of infection and to disseminate systemically.

Mitochondrial dysfunction plays the main role in the regulation of apoptotic cell death (Rudel et al. 2010). The main step in mitochondrion-regulated apoptosis is the permeabilization of the outer 
membrane accompanied by loss of $\Delta \Psi_{\mathrm{m}}$, which is used as an indicator of apoptosis. We observed that macrophage cell death due to $S$. haemolyticus strains was provoked by perturbation of mitochondrial transmembrane potential. The potential significantly decreased to 22 and 9 F.U at 24 and $48 \mathrm{~h}$ after infection. It has been demonstrated that mitochondria are the main target of bacterial proteins that are transferred to host cells during infection (Rudel et al. 2010). Several toxins in a purified form associated with host cells target to mitochondria, inducing $\Delta \Psi_{\mathrm{m}}$ dissipation, cytochrome $c$ release and apoptosis. These include $\alpha$-toxin and PVL of $S$. aureus and pneumolysin of Streptococcus pneumoniae (Genestier et al. 2005; Rudel et al. 2010). All of these toxins create homomultimers which form membrane pores.

In this study, we determined the clonal relatedness of $S$. haemolyticus strains isolated from human specimens. The majority of the strains had unique REP-PCR fingerprint patterns and this indicated that most of the patients were infected with clonally unrelated strains.

The results suggest that infection with S. haemolyticus strains induce apoptosis of host macrophages. The ability of the strains to circumvent the effector function of the phagocytic cells may be an important virulence mechanism of pathogenesis for the persistance and dissemination of the bacteria in the host.

Open Access This article is distributed under the terms of the Creative Commons Attribution License which permits any use, distribution, and reproduction in any medium, provided the original author(s) and the source are credited.

\section{References}

Alexander EH, Rivera FA, Marriott I, Anguita J, Bost KL, Houdson MC (2003) Staphylococcus aureus-induced tumor necrosis factor-related apoptosis-inducing ligand expression mediates apoptosis and caspase- 8 activation in infected osteoblasts. BMC Microbiol 3:5

Böhme L, Rudel T (2009) Host cell death machinery as a target for bacterial pathogens. Microbes Infect 11:1063-1070

Butt HL, Dunstan RH, McGregor NR, Roberts TK, Zerbes M, Klineberg IJ (1998) An association of membrane-damaging toxins from coagulase negative staphylococci and chronic orofacial muscle pain. J Med Microbiol 47:577-584

Ertem GT, Sari T, Hatipoglu CA, Yildiz E, Zarakolu P, Oral B (2010) Peritonitis due to teicoplanin-resistant Staphylococcus haemolyticus. Perit Dial Int 30:117-118
Essmann F, Bantel H, Totzke G, Engels IH, Sinha B, SchulzeOsthoff K, Jänicke RU (2003) Staphylococcus aureus $\alpha$ toxin induced cell death: predominant necrosis despite apoptotic caspase activation. Cell Death Differ 10:1260-1272

Falcone M, Micozzi A, Pompeo ME, Baiochi P, Fabi F, Penni A, Martino P, Venditti M (2004) Methicillin-resistant staphylococcal bacteremia in patients with hematologic malignancies: clinical and microbiological retrospective comparative analysis of $S$. haemolyticus, S. epidermidis and S. aureus. J Chemother 16:540-548

Falcone M, Campanile F, Ganella M, Borbone S, Stefani S, Venditti M (2007) Staphylococcus haemolyticus endocarditis clinical and microbiologic analysis of 4 cases. Diagn Microbiol Infect Dis 57:325-331

Flauhaut S, Vinogradov E, Kelley KA, Brennan S, Hiramatsu K, Lee JC (2008) Structural and biological characterization of capsular polysaccharide produced by Staphylococcus haemolyticus. J Bacteriol 190:1649-1657

Gamberini S, Anania G, Incasa E, Zangirolami A, Tampieri M, Boari B, Benea G, Manfredini R (2006) Staphylococcus haemolyticus liver abscess as an uncommon presentation of silent colonic cancer: a case report. J Am Geriatr Soc 54:1619-1620

Genestier A-L, Michallet M-C, Prevost G, Bellot G, Chalabreysse L, Peyrol S, Thivolet F et al (2005) Staphylococus aureus Panton-Valentine leukocidin directly targets mitochondria and induces Bax-independent apoptosis of human neutrophils. J Clin Invest 115:3117-3127

Harris LG, Richards RG (2006) Staphylococci and implant surfaces: a review. Injury 37:S3-S14

Haslinger-Löffler B, Kahl BC, Grundmeier M, Strangfeld K, Wagner B, Fischer U, Cheung AL, Peters G, SchultzeOsthoff K, Sinha B (2005) Multiple virulence factors are required for Staphylococcus aureus-induced apoptosis in endothelial cells. Cell Microbiol 7:1087-1097

Klingenberg C, Rønnestal A, Anderson AS, Abrahamsen TG, Zorman J, Villaruz A, Flægstad T, Otto M, Sollid JE (2007) Persistent strains of coagulase-negative staphylococci in a neonatal intensive care units:virulence factors and invasiveness. Clin Microbiol Infect 13:1100-1111

Krut O, Utermöhlen O, Schlossherr X, Krönke M (2003) Strainspecific association of cytotoxic activity and virulence of clinical Staphylococcus aureus isolates. Infect Immun 71:2716-2723

Krzymińska S, Mokracka J, Koczura R, Kaznowski A (2009) Cytotoxic activity of Enterobacter cloacae human isolates. FEMS Immunol Med Microbiol 56:248-252

Krzymińska S, Tańska A, Kaznowski A (2011) Aeromonas spp. induce apoptosis of epithelial cells through an oxidantdependent activation of the mitochondrial pathway. J Med Microbiol 60:889-898

Mazzariol A, Lo Cassio G, Kocsis E, Maccacaro L, Fontana R, Cornaglia G (2012) Outbreak of linezolid-resistant Staphylococcus haemolyticus in an Italian intensive care units. Eur J Clin Microbiol Infect Dis 31:523-527

Otto M (2004) Virulence factors of coagulase-negative staphylococci. Front Biosci 9:841-863

Rudel T, Kepp O, Kozjak-Pavlovic V (2010) Interactions between bacterial pathogens and mitochondrial cell death pathways. Nat Microbiol Rev 8:695-705 
Sansonetti PJ, Di Santo JP (2007) Debugging how bacteria manipulate the immune response. Immunity 26:149-161

Shimuta K, Oshnishi M, Iyoda S, Gotoh N, Koizumi N, Watanabe H (2009) The hemolytic and cytotoxic activities of Serratia marcescens phospholipase A (PhlA) depend on lysophospholipid production by PhlA. BMC Microbiol 9:261-271

Spare MK, Tebbs SE, Lang S, Lambert PA, Worthington T, Lipkin GCS, Elliott TSJ (2003) Genotypic and phenotypic properties of coagulase-negative staphylococci causing dialysis catheter-related sepsis. J Hosp Infect 54:272-278

Takueschi F, Watanabe S, Baba T (2005) Whole genome sequencing of Staphylococcus haemolyticus uncovers extreme plasticity of its genome and the evolution of human-colonizing staphylococcal species. J Bacteriol 187:7292-7308
Vasconcelos NG, Pereira VC, Araujo JP, de LRS da Cunha M (2011) Molecular detection of enterotoxins E, G, H and I in Staphylococcus aureus and coagulase-negative staphylococci isolated from clinical samples of newborns in Brazil. J Appl Microbiol 111:749-762

Versalovic J, Koeuth T, Lupski JR (1991) Distribution of repetitive DNA sequences in eubacteria and application to fingerprinting of bacterial genomes. Nucl Acids Res 19:6823-6831

Worth LJ, Slavin MA (2009) Bloodstream infections in haematology: risks and new challenges for prevention. Blood Rev 23:113-122

Zell C, Resch M, Rosestein R, Albrecht T, Hertel C, Götz F (2008) Characterization of toxin production of coagulasenegative streptococci isolated from food and starter cultures. Int J Food Microbiol 127:246-251 